\title{
BMJ Open Association between self-efficacy, career interest and rural career intent in Australian medical students with rural clinical school experience
}

\author{
Vivian Isaac, ${ }^{1}$ Lucie Walters, ${ }^{2}$ Craig S McLachlan ${ }^{1}$
}

To cite: Isaac V, Walters L, McLachlan CS. Association between self-efficacy, career interest and rural career intent in Australian medical students with rural clinical school experience. BMJ Open 2015;5:e009574.

doi:10.1136/bmjopen-2015009574

- Prepublication history for this paper is available online. To view these files please visit the journal online (http://dx.doi.org/10.1136/ bmjopen-2015-009574).

Received 31 July 2015 Revised 25 September 2015 Accepted 20 October 2015

CrossMark

\footnotetext{
${ }^{1}$ Rural Clinical School, University of New South Wales, Sydney, New South Wales, Australia

${ }^{2}$ Rural Clinical School, Flinders University, Adelaide, South Australia, Australia
}

\section{Correspondence to} Dr Craig S McLachlan; reperfusion@hotmail.com

\section{ABSTRACT}

Objectives: To investigate medical student's selfefficacy at the time of finishing their rural clinical school (RCS) placement and factors associated with self-efficacy. Secondary aims are to explore whether interest levels or self-efficacy are associated with rural or remote career intentions.

Design, setting and participants: A crosssectional study of medical students who had completed their RCS term in 17 Australian universities. Data were derived from the 2013 Federation of Rural Australian Medical Educators (FRAME) evaluation survey. Questionnaire responses were analysed from 653 medical students from regional Australia. All 732 students who completed their RCS term in 2013 were invited to participate.

\section{Primary and secondary outcome measures:}

Rural self-efficacy: Six questions to measure selfefficacy beliefs in rural medical practice, based on the sources of self-efficacy described by Bandura. Rural career intention: Students were asked to identify their preferred location for future practice. The options were, Capital or Major City; Inner regional city or large town; Smaller town and very remote area.

Results: Questionnaire responses were analysed from 653 medical students from regional Australia (response rate $89.2 \%$ ). $83.8 \%$ of all students recalled an increase in their interest levels for rural medicine as a result of their RCS experience. Actual career intention to work in a regional area or rural area was $60.2 \%$. Bivariate analyses showed female gender $(p=0.003)$, rural background $(p<0.001)$, an RCS preference for clinical training $(p<0.001)$ and general practice intentions $(p=0.004)$ were factors associated with higher levels of self-efficacy. Logistic regression analyses showed that self-efficacy was independently associated with increased interest in rural medicine (OR $1.4(95 \% \mathrm{Cl} 1.3$ to 1.5$))$ and rural career intent (OR $1.2(95 \% \mathrm{Cl} 1.1$ to 1.3)). (Model included gender, rural background, preference for RCS, generalist intent, rural practice interest and selfefficacy).

Conclusions: Self-efficacy is associated with increased interest levels for rural medicine and rural medical career intent.

\section{Strengths and limitations of this study}

- Currently there is a maldistribution of doctors across urban, rural and remote areas of Australia. We may improve the distribution of future doctors to areas of workforce need by using selection and training processes based on assessing medical student's psychosocial and cognitive factors.

- The study provides valuable information on the association between, self-efficacy, career interest and rural career intention among medical students.

- Data were derived from the longitudinal tracking study of Federation of Rural Australian Medical Educators (FRAME) of Australian Rural Clinical Schools with consistent definitions, agreed protocols and mechanisms for collecting and reporting data at the national level.

- The study is limited by its cross-sectional design and therefore causation cannot be inferred.

\section{INTRODUCTION}

Australia faces considerable challenges in meeting doctor supply needs. A maldistribution (under supply) of doctors to regional and remote Australia exists. For example, the Australian bureau of statistics estimated in 2011, that the per capita ratio of primary care doctors in major cities was double compared to remote and regional areas. ${ }^{1}$ There is a need to address and understand career psychosocial motivations for rural and remote practice. It remains unknown whether earlier educational work experiences can enhance rural or remote clinical career self-efficacy.

Self-efficacy is a cognitive structure created by the cumulative learning experiences in a person's life that lead to development of belief or expectation that they can or cannot successfully perform a specific task or activity. $^{2}{ }^{3}$ Self-efficacy as a psychological construct, has been well described in career 
choice models to explain career behaviours. ${ }^{4}{ }^{5}$ Lent et $a t^{6}$ and Roger and Creed ${ }^{7}$ have demonstrated that selfefficacy served as an antecedent of outcome expectations, interests and goals for career planning and career exploration in high school and university students. Business individuals demonstrate prior high self-efficacy for entrepreneurial intentions and beliefs before the creation of a new enterprise. ${ }^{89}$ This suggests intention and actual practice can be associated with prior self-efficacy values for a specific future activity.

Over the past 15 years, the Australian government has invested in a number of large scale national programmes to develop medical students training in rural medicine. These programmes have included the Rural Undergraduate Support and Co-ordination, University Departments of Rural Health and the Rural Clinical Schools (RCS) programmes. ${ }^{10}$ The RCS programme is the largest in terms of scale, infrastructure development and scope and was launched in 2000 to enable medical students to undertake extended blocks of their clinical training in regional areas. Australian rural clinical schools permit students from either urban or rural backgrounds to attend a RCS campus. Within a medical faculty, Australian RCS are responsible for delivering a year or more of the clinical medical curriculum in a rural environment, for $25 \%$ of medical students. ${ }^{11}$

RCS outcomes and medical student rural career intent have been extensively evaluated and have traditionally focused on extrinsic outcome factors to predict rural work force outcomes. Extrinsic factors have included previous rural background, gender, scholarships, length of time spent at an RCS and specialty preference as predictors of intended rural practice after graduation. ${ }^{12} 13$ Few studies have addressed psychosocial aspects to rural medical career development. One study has previously investigated the role of personality domains on rural career intentions and showed that the probability of rural preference was greater with higher scores of openness to experience, agreeableness and self-confidence but lower with higher scores on extraversion, autonomy and intraception. ${ }^{14}$ On the other hand it has been suggested that the influence of personality factors on human career decision functioning is insufficient. Self-efficacy as a predictor in addition to rural background, rural training, rural and generalist intent has been used in an index to predict rural career choice. ${ }^{15}$ Career interest and self-efficacy expectations have been suggested to influence career choice ${ }^{16}{ }^{17}$ and selfefficacy to mediate the relationship between personality and career interest. ${ }^{18}$

Across Australian RCS programmes, the application of social cognitive career theory on rural medical career intent requires further understanding in the context of a specific RCS experience. The longitudinal tracking survey of the Federation of Rural Australian Medical Educators (FRAME), for Australian Rural Clinical Schools has consistent definitions, agreed protocols and mechanisms for collecting and reporting data at a national level. ${ }^{19}$ This survey tool provides opportunities for assessing self-efficacy in a rural clinical school environment. The purpose of this study is to investigate medical student's self-efficacy at the time of finishing their RCS placement and factors associated with selfefficacy (via the FRAME survey). ${ }^{20}$ Secondary aims are to explore whether interest levels or self-efficacy are associated with rural or remote career intentions.

\section{METHODS}

Australian RCS and Rural Medical Schools (RMS) have collaborated through FRAME to develop a national exit questionnaire to collect demographic, educational, experiential and intentional career data from students completing their RCS experience. The survey is an evaluation tool distributed to medical students who had completed their RCS term in all 17 Australian universities each year. In the survey instrument 'FRAME Rural Clinical School Survey 2013' we had included additional questions on rural self-efficacy. All 732 students who had completed their RCS term in 2013 were invited to participate.

\section{Measurements}

Rural self-efficacy: To measure self-efficacy beliefs in rural medical practice, the rural self-efficacy questions were developed. In total, there were six questions that measured individual's self-efficacy to practice in rural setting (table 1). These survey questions were developed as there were no previously known measurements for assessing career self-efficacy in Australian medical students attending a rural campus. The questions were developed based on the five sources of self-efficacy, that is, vicarious learning, verbal persuasion, positive emotional arousal, negative emotional arousal and performance accomplishments (figure 1). ${ }^{3}$ We used questions focused on these sources of self-efficacy to calculate a composite rural medicine self-efficacy score. This score was

Table 1 Frame survey questions aligned with Bandura's five sources of self-efficacy

\begin{tabular}{ll}
$\begin{array}{l}\text { Sources of } \\
\text { self-efficacy }\end{array}$ & Questions \\
\hline $\begin{array}{l}\text { Performance } \\
\text { accomplishments }\end{array}$ & $\begin{array}{l}\text { Rural practice is too hard } \\
\text { I have necessary skills to } \\
\text { practice in rural setting } \\
\text { I get a sinking (anxious) feeling } \\
\text { when I think of working in rural } \\
\text { setting }\end{array}$ \\
$\begin{array}{l}\text { Negative emotional } \\
\text { arousal }\end{array}$ & $\begin{array}{l}\text { I have a strong positive feeling } \\
\text { when I think of working in a rural } \\
\text { setting }\end{array}$ \\
Positive emotional & $\begin{array}{l}\text { People tell me I should work in a } \\
\text { rural setting } \\
\text { I see people like me taking up } \\
\text { Verbal persuasion }\end{array}$ \\
Vicarious learning & clinical practice
\end{tabular}




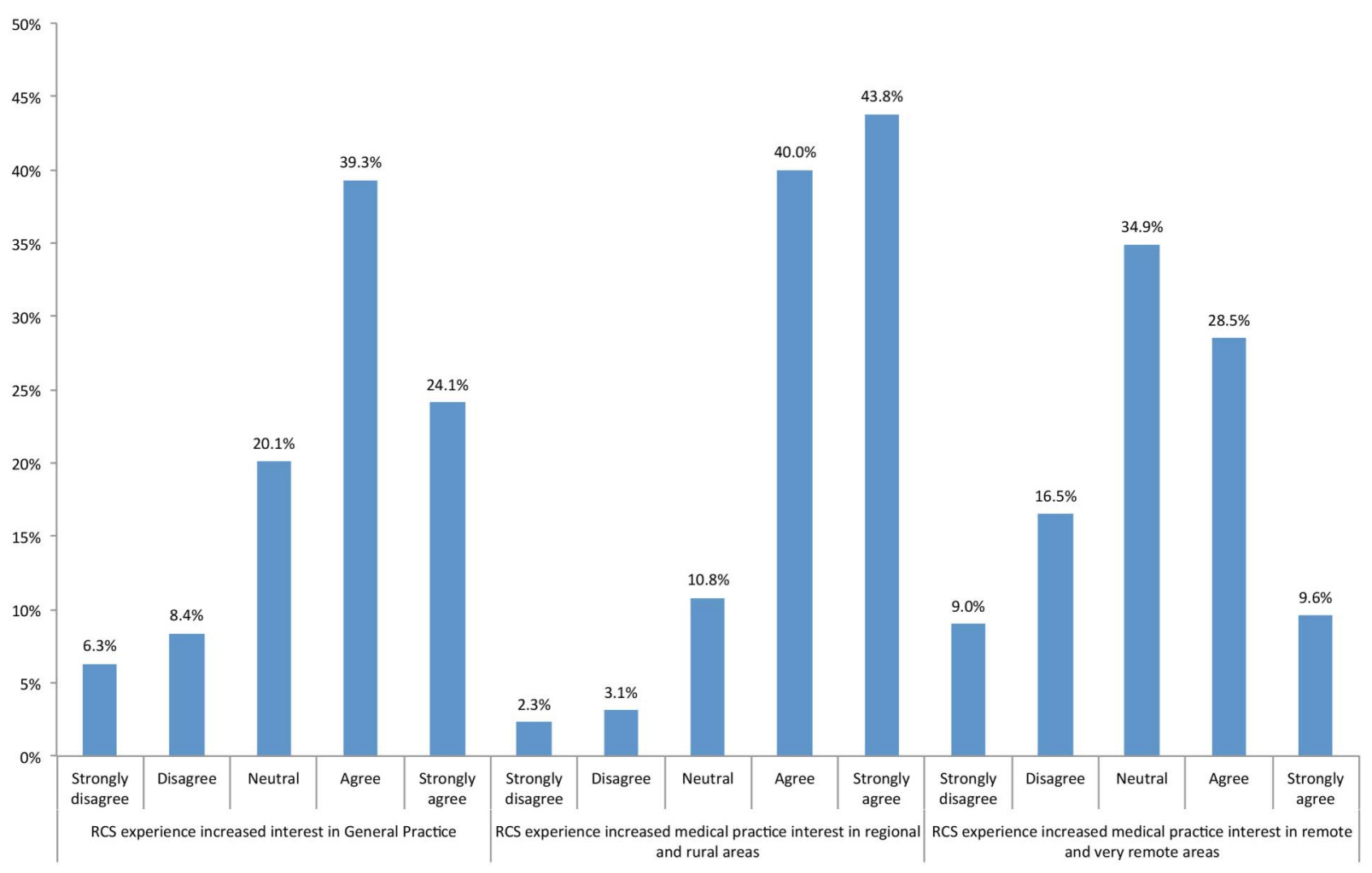

Figure 1 Retrospective evaluation of change in career interest. The figure illustrates medical student's retrospective evaluation of change in interest as a result of RCS experience to practice in regional and rural areas and remote and very remote areas.

calculated from the Likert scale score of each of the questions. Negative scoring applied to the two negatively (questions 1 and 3) framed questions before calculating the composite score, which could range from 6 to 30 . These questions as a scale demonstrated an internal reliability (Cronbach $\alpha$ ) of 0.78 in the present sample. Construct validity was demonstrated with significant correlation with rural career interest and self-efficacy score $(\mathrm{r}=0.50, \mathrm{p}<0.001)$.

Change in interest in rural practice: Retrospectively students evaluated their change in interest for rural medicine as a result of their RCS experience in a 5-point Likert scale. "My RCS medical experience has increased my interest in pursuing a career in a medical career in regional or rural Australia" Strongly disagree, somewhat disagree, neutral, somewhat agree, strongly agree. Similarly students accessed their interest in general practice.

Rural career intention: Students were asked to identify their preferred location for future practice. "In which geographical location within Australia would you most like to practice on completing your training?" The options were, Capital or Major City; Inner regional city or large town in Australia (25 000-100 000); Smaller town-outer regional (10 000-24 999); Small rural or remote communities (10000) and Very remote centre/ area.

Other variables included in the analyses were gender, rural background, preference for RCS clinical training and preference for speciality or general practice at entry.

\section{Data analyses}

Data were analysed using the statistical package SPSS V. 21 (SPSS IBM, New York, USA). Descriptive data were examined to determine study variables. Pearson's t test or one-way ANOVA test was used to determine the factors associated with self-efficacy. Post hoc LSD analyses were used to understand specific differences between categories. A step-wise logistic regression model was used to analyse the independent association between self-efficacy and interest levels in rural practice at exit from an RCS; likewise, analysed the independent association between self-efficacy and rural career intention. Gender, rural background and RCS preference, generalist intent, interest and self-efficacy were included in the models as applicable. Cox and Shell $R^{2}$ were used to show the variance explained by self-efficacy on increased interest and intent in rural practice respectively.

\section{RESULTS}

Data were analysed from 653 medical student respondents (response rate: 89.2\%) from regional Australia, $58.8 \%$ were female students. The descriptive details of the study variables are presented in table 2 . The survey results show that $41.9 \%$ considered they had come from a rural background. General practice (family medicine) was the intended career in $28.7 \%$ of the students. Preference for RCS clinical training as student's first choice was reported to be $65.7 \%$, while a further $16.4 \%$ 
Table 2 Characteristics of the sample

\begin{tabular}{|c|c|c|}
\hline Characteristics & $\mathbf{N}$ & Per cent \\
\hline \multicolumn{3}{|l|}{ Gender } \\
\hline Male & 269 & 41.2 \\
\hline Female & 384 & 58.8 \\
\hline \multicolumn{3}{|l|}{ Rural background } \\
\hline No & 371 & 57.4 \\
\hline Yes & 275 & 42.6 \\
\hline \multicolumn{3}{|c|}{ Type of location living longest in Australia } \\
\hline Capital city & 280 & 43.9 \\
\hline Major city & 75 & 11.8 \\
\hline Regional & 109 & 17.1 \\
\hline Rural & 69 & 10.8 \\
\hline Small rural & 96 & 15.0 \\
\hline Remote & 9 & 1.4 \\
\hline \multicolumn{3}{|c|}{ Preference for RCS for clinical training } \\
\hline Last choice & 28 & 4.3 \\
\hline Low on list & 26 & 4.0 \\
\hline Mid-choice & 61 & 9.4 \\
\hline High on list & 106 & 16.4 \\
\hline First choice & 425 & 65.8 \\
\hline \multicolumn{3}{|c|}{ Preferred location for work } \\
\hline Capital/major city & 245 & 37.5 \\
\hline Regional & 225 & 34.5 \\
\hline Rural & 125 & 19.1 \\
\hline Small rural & 43 & 6.6 \\
\hline Remote & 7 & 1.1 \\
\hline \multicolumn{3}{|c|}{ Career preference at entry to RCS } \\
\hline General practice & 188 & 29.1 \\
\hline Generalist specialist & 274 & 42.8 \\
\hline Subspecialist/others & 185 & 28.6 \\
\hline \multicolumn{3}{|c|}{ Current career preference at exit from RCS } \\
\hline General practice & 188 & 28.8 \\
\hline Generalist specialist & 273 & 41.8 \\
\hline Subspecialist/others & 182 & 27.9 \\
\hline
\end{tabular}

reported the RCS ranking high on their list for clinical training. The results (figure 1) show that $63.4 \%$ reported an increased level of interest in general practice as a result of their RCS experience. In total 83.8\% of students reported an increase in their interest levels for rural medicine as a result of their RCS experience,
$61.3 \%$ favoured career intentions for either a regional, rural or remote location (table 1). Career intentions for an eventual urban location were $37.5 \%$.

The mean (SD) composite score of the six rural career self-efficacy questions was 22.9 (3.5). The descriptive information of each question is reported in table 3 . Table 4 explores the factors associated with rural selfefficacy. Rural self-efficacy was associated with gender, that is, female students had higher self-efficacy compared to male students $(\mathrm{t}=-2.9, \mathrm{p}=0.003)$; rural background $(\mathrm{t}=-5.9, \mathrm{p}<0.001)$; higher preference for RCS clinical training $(\mathrm{t}=-6.2, \mathrm{p}<0.001)$; and general practice intention at entry to RCS ( $t=5.5, p=0.004)$

Rural self-efficacy was associated with increased interest in general practice $(\mathrm{t}=-7.2, \mathrm{p}<0.001)$ and increased interest in rural $(\mathrm{t}=-10.2, \mathrm{p}<0.001)$ or remote practice $(\mathrm{t}=-7.4, \mathrm{p}<0.001)$. Self-efficacy scores gradually increased based on intention to practice farthest to a Capital city (remote areas). The self-efficacy score at capital city was 21.2 (SD 3.1), whereas the self-efficacy of students intent to practice in small rural or remote areas was 25.2 (SD $3.9)$ and the difference was statistically significant ( $t=8.6$, $\mathrm{p}<0.001)$. The number of students wishing to practice in a small rural or remote area was $7.7 \%$ of the cohort (table 1).

Table 5 explains the multivariate logistic regression analyses on the effect of self-efficacy in rural career interest and rural career intent. RCS preference (OR 2.1 (95\% CI 1.2 to 3.7$)$ ) and self-efficacy (OR 1.4 (95\% CI 1.3 to 1.5)) were independently associated with increased interest in rural medical practice due to RCS training. Cox and Shell $\mathrm{R}^{2}$ suggests self-efficacy could explain an additional $10 \%$ in predicting students with increased levels of interest in rural practice. Gender OR 1.9 (95\% CI 1.2 to 2.9$)$, rural background OR $2.7(95 \%$ CI 1.8 to 4.3 ), preferred RCS OR 2.5 (95\% CI 1.2 to $5.5)$, general practice intention at entry OR $3.5(95 \%$ CI 2.9 to 5.5 ), increase interest due to RCS training OR 2.6 (95\% CI 1.1 to 6.3 ) were associated with rural intentions. In addition, self-efficacy was independently associated with rural practice intention after adjustment for gender, rural background, preferred RCS, general practice intention at entry, increase interest due to RCS training OR 1.2 (95\% CI 1.1 to 1.3$)$.

Table 3 Self-efficacy in rural practice

\begin{tabular}{|c|c|c|c|c|c|}
\hline Questions & $\mathbf{N}$ & $\begin{array}{l}\text { Mean } \\
\text { (SD) }\end{array}$ & $\begin{array}{l}\text { Strongly disagree/ } \\
\text { disagree (\%) }\end{array}$ & $\begin{array}{l}\text { Neutral } \\
(\%)\end{array}$ & $\begin{array}{l}\text { Strongly agree/ } \\
\text { agree (\%) }\end{array}$ \\
\hline Rural practice is too hard & 645 & $2.06(0.70)$ & 79.2 & 15.7 & 5.1 \\
\hline I have necessary skills to practice in rural setting & 644 & $3.75(0.73)$ & 6.7 & 20.7 & 72.6 \\
\hline $\begin{array}{l}\text { I get a sinking (anxious) feeling when I think of } \\
\text { working in rural setting }\end{array}$ & 643 & $1.98(0.91)$ & 75.6 & 18.3 & 5.6 \\
\hline $\begin{array}{l}\text { I have a strong positive feeling when I think of } \\
\text { working in a rural setting }\end{array}$ & 645 & $3.83(0.83)$ & 6.4 & 22.6 & 69.6 \\
\hline People tell me I should work in a rural setting & 643 & $3.72(0.91)$ & 8.9 & 28 & 61.3 \\
\hline I see people like me taking up rural clinical practice & 644 & $3.66(0.93)$ & 11.3 & 24.5 & 62.5 \\
\hline Mean composite score & 640 & $22.9(3.6)$ & & & \\
\hline
\end{tabular}


Table 4 Factors associated with self-efficacy in rural practice

\begin{tabular}{|c|c|c|c|}
\hline & \multicolumn{3}{|c|}{ Self-efficacy } \\
\hline & $\mathbf{N}$ & Mean (SD) & $t / f$ (p value) \\
\hline \multicolumn{4}{|l|}{ Gender } \\
\hline Male & 264 & $22.4(3.3)$ & \multirow[t]{2}{*}{$-2.9(0.003)$} \\
\hline Female & 376 & $23.3(3.6)$ & \\
\hline \multicolumn{4}{|l|}{ Rural background } \\
\hline No & 361 & $22.2(3.3)$ & \multirow[t]{2}{*}{$-5.9(<0.001)$} \\
\hline Yes & 272 & $23.8(3.6)$ & \\
\hline \multicolumn{4}{|l|}{ Type of location living longest in Australia } \\
\hline Capital city/major city & 347 & $23.1(3.4)$ & \multirow[t]{4}{*}{$0.6(0.63)$} \\
\hline Regional & 107 & $22.8(3.6)$ & \\
\hline Rural & 66 & $22.6(4.1)$ & \\
\hline Small rural/remote & 105 & $22.7(3.3)$ & \\
\hline \multicolumn{4}{|l|}{ Preference for RCS for clinical training } \\
\hline Last/low/mid-choice & 109 & $21.1(3.3)$ & \multirow[t]{2}{*}{$-6.2(<0.001)$} \\
\hline First/high on list & 524 & $23.3(3.4)$ & \\
\hline \multicolumn{4}{|l|}{ Intended speciality at entry to RCS } \\
\hline General practice & 185 & $23.5(3.4)$ & \multirow[t]{3}{*}{$5.5(0.004)$} \\
\hline Generalist specialist & 268 & $22.8(3.2)$ & \\
\hline Subspecialist/others & 183 & $22.3(3.7)$ & \\
\hline \multicolumn{4}{|c|}{ Career interest } \\
\hline \multicolumn{4}{|c|}{ RCS experience increased interest in general practice } \\
\hline Strongly disagree/disagree/neutral & 223 & $21.6(3.7)$ & \multirow{2}{*}{$-7.2(<0.001)$} \\
\hline Strongly agree/agree & 409 & $23.6(3.1)$ & \\
\hline \multicolumn{4}{|c|}{ RCS experience increased interest in medical practice in regional and rural areas } \\
\hline Strongly disagree/disagree/neutral & 103 & $19.9(3.9)$ & \multirow[t]{2}{*}{$-10.2(<0.001)$} \\
\hline Strongly agree/agree & 533 & $23.5(3.1)$ & \\
\hline \multicolumn{4}{|c|}{ RCS experience increased interest in medical practice in remote and very remote areas } \\
\hline Strongly disagree/disagree/neutral & 388 & $22.1(3.6)$ & \multirow[t]{2}{*}{$-7.4(<0.001)$} \\
\hline Strongly agree/agree & 246 & $24.2(2.9)$ & \\
\hline \multicolumn{4}{|c|}{ Career intention } \\
\hline \multicolumn{4}{|c|}{ Preferred location for work at exit from RCS } \\
\hline Capital/major city & 238 & $21.2(3.1)$ & \multirow[t]{4}{*}{$46.7(<0.001)$} \\
\hline Regional & 221 & $23.3(3.2)$ & \\
\hline Rural & 124 & $24.7(2.6)$ & \\
\hline Small rural/remote & 49 & 25.2 (3.9) & \\
\hline
\end{tabular}

\section{DISCUSSION}

Previous studies have demonstrated that a rural medical student placements exhibit significant influence on rural career interest and intentions. ${ }^{10}$ More recently it has been shown that length of time at a RCS increases rural career interest levels. ${ }^{21}$ In the present study we have found that self-efficacy explains $20 \%$ of the variance in rural practice interest levels by medical students that have attended an RCS. In the present study both increased rural career interest levels and rural selfefficacy were found to be independently associated with rural career intent. Importantly we note in our study that most $(>80 \%)$ students developed an increased interest to practice in a rural area, but not for remote and smaller rural areas. This may suggest that self-efficacy increase is greatest in environments where the RCS is located and experiences are associated. In the FRAME survey cohort most RCS's are located typically in larger rural towns and regional cities. ${ }^{11}$
Rural background is a strong influence on rural medical practice intent among medical students. ${ }^{12} 22{ }^{23}$ Students who have a rural background are more than twice likely to become rural practitioners. In our study, we show rural background is associated with higher rural self-efficacy. Rural exposure via education, recreation and upbringing has been suggested to provide the familiarity, sense of place and community involvement could motivate medical students towards both intended and actual rural careers. ${ }^{24}$ This finding is consistent with the self-efficacy literature which describes self-efficacy as a construct that encompasses motivation, adjustment and interest. ${ }^{45}$ Our study is consistent with previous studies that found close associations between rural background, rural intent and selfefficacy. ${ }^{15}$ Additionally we show self-efficacy and career interest are associated with rural career intention, independent of the medical student's rural background.

Social-cognitive career theory suggests that vocational interests develop over time, partially as a function of self- 
Table 5 Logistic regression analysis for the effect of self-efficacy on rural career intention

\begin{tabular}{|c|c|c|c|c|c|}
\hline & \multicolumn{2}{|c|}{$\begin{array}{l}\text { Increased interest in rural } \\
\text { medical practice }\end{array}$} & \multicolumn{3}{|c|}{ Intention to practice in rural areas } \\
\hline & $\begin{array}{l}\text { Model } 1 \\
\text { OR }(95 \% \mathrm{Cl})\end{array}$ & $\begin{array}{l}\text { Model } 2 \\
\text { OR }(95 \% \mathrm{Cl})\end{array}$ & $\begin{array}{l}\text { Model A } \\
\text { OR }(95 \% \mathrm{Cl})\end{array}$ & $\begin{array}{l}\text { Model B } \\
\text { OR }(95 \% \mathrm{Cl})\end{array}$ & $\begin{array}{l}\text { Model C } \\
\text { OR }(95 \% \mathrm{Cl})\end{array}$ \\
\hline Gender (female) & $1.5(1.0 \text { to } 2.5)^{*}$ & $1.5(0.9$ to 2.5$)$ & $2.2(1.4 \text { to } 3.2)^{\star *}$ & $2.0(1.3 \text { to } 3.1)^{*}$ & $1.9(1.2 \text { to } 2.9)^{*}$ \\
\hline Rural background & 1.3 (0.9 to 2.2$)$ & $1.0(0.6$ to 1.7$)$ & $3.5(2.4 \text { to } 5.4)^{\star *}$ & $3.5(2.3 \text { to } 5.3)^{* *}$ & $2.7(1.8 \text { to } 4.3)^{\star \star}$ \\
\hline Preferred RCS & $3.4(2.1 \text { to } 5.6)^{\star \star}$ & $2.1(1.2 \text { to } 3.7)^{\star \star}$ & $4.3(2.1 \text { to } 9.0)^{\star *}$ & $3.6(1.7 \text { to } 7.7)^{\star \star}$ & $2.5(1.2 \text { to } 5.5)^{*}$ \\
\hline General practice intention at entry & 0.8 (0.5 to 1.3$)$ & & $3.3(2.2 \text { to } 4.9)^{\star *}$ & $3.5(2.3 \text { to } 5.3)^{\star *}$ & $3.5(2.9 \text { to } 5.5)^{\star \star}$ \\
\hline Increased interest in rural medical practice & & & & $4.2(1.8 \text { to } 9.3)^{\star *}$ & $2.6(1.1 \text { to } 6.3)^{*}$ \\
\hline Self-efficacy score & & $1.4(1.3 \text { to } 1.5)^{\star *}$ & & & $1.2(1.1 \text { to } 1.3)^{\star \star}$ \\
\hline Model $\chi^{2}$ & 29.2 & 100.8 & 135.0 & 147.8 & 180.7 \\
\hline Cox and Shell $\mathrm{R}^{2}$ & 0.04 & 0.14 & 0.19 & 0.21 & 0.25 \\
\hline
\end{tabular}

${ }^{*} p<0.05,{ }^{* *} p<0.001$.

RCS, rural clinical school.

efficacy expectations. ${ }^{6}$ Several studies have noted a relationship between self-efficacy and career interest levels. $^{26} \quad 27$ Among medical students, Bierer et $a l^{28}$ explained an association between research self-efficacy and interest in clinical research careers. In our study we have demonstrated a positive relationship between increased self-efficacy and rural practice interest levels in medical students. Interest level has been poorly studied with respect to Australian medical student's rural educational experiences and career interest or intent for rural practice. ${ }^{21}$ Other studies have attempted to model selfefficacy on medical students with rural backgrounds on rural career intentions in the absence of rural career interest levels. ${ }^{15}$ Indeed others have shown an improvement in understanding career intentions by studying both career interest and self-efficacy. ${ }^{26}$

Longitudinal rural placement enables students to achieve personal goals, and enhance beliefs and orientation towards the complex personal and professional demands of rural practice. ${ }^{24}$ This is paralleled with an incremental increase in rural career intentions, with each additional year of RCS training that students undertake. $^{29}$ Further career interest in rural practice may increase after 1-year of RCS training. ${ }^{21}$ Increased self-efficacy through rural training may explain the increased interest and intention to practice in a rural area. Indeed in the present study we demonstrate that rural career self-efficacy explains additional variance in rural career interest and career intent. We also found that rural career self-efficacy levels modulate career choice intentions in rural and urban students. These associations are cross-sectional and could not determine causality. Only students of RCS participated in the study, therefore generalisation to all medical students should be considered cautiously. Nevertheless there is likely a need to establish whether self-efficacy is an integral part of rural placement curriculum and experience. To do this we suggest that longitudinal tracking of rural career intentions among medical students on actual and eventual rural practice are evaluated, particularly with respect to change in self-efficacy and interest levels.
Our study has particular strengths, that include all data were derived from the longitudinal tracking study of FRAME of Australian RC S. The study survey tool has consistent definitions, agreed protocols and mechanisms for collecting and reporting data at the national level. This is the first time that FRAME survey has had selfefficacy questions introduced. We acknowledge that no previous questionnaire to measure self-efficacy in our rural medical students has been available that encompasses the five factors of self-efficacy described by Bandura $^{3}$ Our adapted survey questions to access selfefficacy produced a $\kappa$ of 0.78 in the present study, which shows the items' have good internal consistency for group comparison. ${ }^{30}$ Our questions are associated with change in self-interest for rural practice as a function of rural clinical experience. This supports the notion that our self-efficacy questions are indeed assessing social cognitive elements of career intent.

In conclusion, we found students from rural backgrounds to have higher self-efficacy following training at a RCS. These higher levels of self-efficacy were associated with higher levels of career intent to practice in rural areas. We have shown that self-efficacy is associated with increased interest levels for rural medicine and rural medical career intent. Early identification of low self-efficacy in potential RCS students may suggest these students are unlikely to benefit from an RCS experience in terms of enhancing interest in rural medical careers. As we have found students with low self-efficacy on exit from an RCS are less likely to develop rural career pathway intentions. The concept for developing learning opportunities in more remote areas to increase remote clinical self-efficacy is suggested. This may translate to additional remote rural clinical practice intentions.

Twitter Follow Lucie Walters at @Lucie.waltersRG

Contributors VI developed the study design and the self-efficacy survey questions which were added to the standard FRAME survey; and analysed the data and drafted the initial version of the manuscript. LW contributed to initial project design, data interpretation and critical revision of the manuscript. CSM contributed to initial project design, data interpretation and critical revision of the manuscript. All approved the final manuscript. 
Funding All Rural Clinical Schools involved are funded by the Commonwealth Government of Australia.

Competing interests $\mathrm{VI}$ is a $\mathrm{PhD}$ student in an Australian rural clinical school. LW has direct leadership responsibilities for a medical student education programme in an Australian rural clinical school. Students from her programme participated in the FRAME exit survey. CSM has leadership responsibilities for a medical student education programme in an Australian rural clinical school.

Ethics approval Flinders University, South Australia.

Provenance and peer review Not commissioned; externally peer reviewed.

Data sharing statement No additional data are available.

Open Access This is an Open Access article distributed in accordance with the Creative Commons Attribution Non Commercial (CC BY-NC 4.0) license, which permits others to distribute, remix, adapt, build upon this work noncommercially, and license their derivative works on different terms, provided the original work is properly cited and the use is non-commercial. See: http:// creativecommons.org/licenses/by-nc/4.0/

\section{REFERENCES}

1. ABS. Australian Bureau of Statistics, 2011, Australian Social Trends, cat. no. 4102.0. Secondary Australian Bureau of Statistics, 2011, Australian Social Trends, cat. no. 4102.0 2011. http://www.abs.gov. au/AUSSTATS

2. Bandura A. Social foundations of thought and action: a social cognitive theory. Englewood Cliffs, NJ: Prentice-Hall, 1986.

3. Bandura A. Self-efficacy: toward a unifying theory of behavioral change. Psychol Rev 1977;84:191-215

4. Niles SG, Sowa CJ. Mapping the nomological network of career self efficacy. Career Dev Q 1992;41:13-21.

5. Anderson SL, Betz NE. Sources of social self-efficacy expectations: their measurement and relation to career development. $J$ Vocational Behav 2001;58:98-117.

6. Lent RW, Sheu H-B, Singley D, et al. Longitudinal relations of self-efficacy to outcome expectations, interests, and major choice goals in engineering students. J Vocational Beh 2008;73:328-35.

7. Rogers ME, Creed PA. A longitudinal examination of adolescent career planning and exploration using a social cognitive career theory framework. J Adolesc 2011;34:163-72.

8. Boyd NG, Vozikis GS. The influence of self-efficacy on the development of entrepreneurial intentions and actions. Entrepreneurship Theory Pract 1994;18:63-90.

9. Segal G, Borgia D, Schoenfeld J. The motivation to become an entrepreneur. Int J Entrepreneurial Behav Res 2005;11:42-57.

10. Walker JH, Dewitt DE, Pallant JF, et al. Rural origin plus a rural clinical school placement is a significant predictor of medical students' intentions to practice rurally: a multi-university study. Rural Remote Health 2012;12:1908.

11. The Department of Health. Rural Clinical Training and Support Secondary The Department of Health. Rural Clinical Training and Support. http://www.health.gov.au/clinicalschools

12. Somers GT, Strasser R, Jolly B. What does it take? The influence of rural upbringing and sense of rural background on medical students' intention to work in a rural environment. Rural Remote Health 2007;7:706

13. Jones M, Humphreys J, Prideaux D. Predicting medical students intentions to take up rural practice after graduation. Med Educ 2009;43:1001-9.

14. Jones MP, Eley D, Lampe L, et al. Role of personality in medical students' initial intention to become rural doctors. Aust J Rural Health 2013;21:80-9.

15. Somers GT, Jolly B, Strasser RP. The SOMERS Index: a simple instrument designed to predict the likelihood of rural career choice. Aust J Rural Health 2011;19:75-80.

16. Lent RW, Brown SD, Hackett G. Toward a unifying social cognitive theory of career and academic interest, choice, and performance. $J$ Vocational Behav 1994;45:79-122.

17. Rottinghaus PJ, Lindley LD, Green MA, et al. Educational aspirations: the contribution of personality, self-efficacy, and interests. J Vocational Behav 2002;61:1-19.

18. Nauta MM. Self-efficacy as a mediator of the relationships between personality factors and career interests. J Career Assess 2004;12:381-94.

19. DeWitt DE, McLean R, Newbury J, et al. Development of a common national questionnaire to evaluate student perceptions about the Australian Rural Clinical Schools Program. Rural Remote Health 2005;5:486.

20. FRAME. Federation of Rural Australian Medical Educators. Secondary Federation of Rural Australian Medical Educators. http:// www.ausframe.org

21. Isaac V, Watts L, Forster L, et al. The influence of rural clinical school experiences on medical students' levels of interest in rura careers. Hum Resour Health 2014;12:48.

22. Laven G, Wilkinson D. Rural doctors and rural backgrounds: how strong is the evidence? A systematic review. Aust J Rural Health 2003;11:277-84.

23. Laven GA, Wilkinson D, Beilby JJ, et al. Empiric validation of the rural Australian Medical Undergraduate Scholarship 'rural background' criterion. Aust J Rural Health 2005;13:137-41.

24. Hancock C, Steinbach A, Nesbitt TS, et al. Why doctors choose small towns: a developmental model of rural physician recruitment and retention. Soc Sci Med 2009;69:1368-76.

25. Somers GT, Spencer RJ. Nature or nurture: the effect of undergraduate rural clinical rotations on pre-existent rural career choice likelihood as measured by the SOMERS Index. Aust J Rural Health 2012;20:80-7.

26. Lent RW, Sheu HB, Brown SD. The self-efficacy-interest relationship and RIASEC type: which is figure and which is ground? Comment on Armstrong and Vogel (2009). J Couns Psychol 2010;57:219-25.

27. Fillman VM. Career interest, self-efficacy, and perception in undecided and nursing undergraduate students: a quantitative study. Nurse Educ Today 2015;35:251-5

28. Bierer SB, Prayson RA, Dannefer EF. Association of research self-efficacy with medical student career interests, specialization, and scholarship: a case study. Adv Health Sci Educ Theory Pract 2015;20:339-54.

29. Forster L, Assareh H, Watts LD, et al. Additional years of Australian Rural Clinical School undergraduate training is associated with rural practice. BMC Med Educ 2013;13:37.

30. Streiner DL. Starting at the beginning: an introduction to coefficient alpha and internal consistency. J Pers Assess 2003;80:99-103. 